\section{“MONUMENTO AL ROTO... PIOJENTO": LA CONSTRUCCIÓN OLIGÁRQUICA DE LA IDENTIDAD NACIONAL EN CHILE}

\author{
Gloria Cortés Aliaga \\ Centro de Documentación de las Artes, Santiago de Chile \\ Plaza de la ciudadanía n. ${ }^{\circ} 26$, Nivel - 3 \\ Centro Cultural Palacio La Moneda \\ Santiago, Chile \\ cortes.gloria@gmail.com
}

\section{“MONUMENT IN HONOUR OF THE LOUSY... ROTO": THE OLIGARCHIC CONSTRUCTION OF THE NATIONAL IDENTITY IN CHILE}

\begin{abstract}
The 19th Century is, perhaps, one of the most complex period of the chilean's history as a builder of a national identity. One image that is developed throughout the century, and that will put face to face the intellectuals with the traditional oligarchy will be the one of the "roto chileno", in an attempt to establish the construction of an iconographic repertoire of a Modern Republic and a country-image, but mainly oriented to define a social class, which was strongly sustained in an imaginary constructed in favor of its own interests.
\end{abstract}

KEY WORDS: Chile; 19th Century; identity; chilean "roto".

AvatARES ICÓNICOS EN LA CONSTRUCCIÓN DE UNA MEMORIA HISTÓRICA CHILENA

\begin{abstract}
"iOjalá señores, que esta estátua, que inmortaliza al labriego trocado en soldado heroico, nos recuerde todos los días i a todas horas, a grandes i pequeños, a las autoridades $i$ a los simples ciudadanos, la obligación estricta que nos cabe de contribuir, en la medida de nuestras fuerzas, a mejorar la condicion del pueblo!" (Nercasseau, 1888)'.
\end{abstract}

Con estas palabras, un nuevo grupo de intelectuales liberales, demócratas e ilustrados demandaba mayores oportunidades para el pueblo chileno, y abogando a mejoras educacionales y laborales se ensalzó un nuevo estereotipo sobre el cual el gobierno debía poner sus ojos: el bajo pueblo en la figura del Roto Chileno. El camino hacia la modernización se enfrentaba con la visión tradicional de liberales, radicales y oligárquicos en la búsqueda de resolver las demandas del siglo XIX.
RESUMEN: El siglo XIX es, quizás, uno de los períodos más complejos de la historia chilena en cuanto a constructor de una identidad nacional. Una imagen que se desarrolla a lo largo de la centuria, y que enfrentará a intelectuales y a la oligarquía tradicional, será la del roto Chileno, en un intento de establecer un repertorio iconográfico de construcción de una República Moderna y una imagen-país. Pero orientada, fundamentalmente, a la afirmación de una clase social, que se sustentaba con fuerza en un imaginario construido a favor de sus propios intereses.

PALABRAS CLAVE: Chile; siglo XIX; identidad; roto chileno.

¿Pero, en qué momento la figura del "Roto" reemplaza al "hombre ilustre" y se transforma en un imaginario nacional? En el devenir de nuestra historia, los monumentos y sus referentes iconográficos fueron concebidos según las necesidades de la República y los grupos sostenedores del poder, desde los cuales se definió una construcción simbólica en torno a los conceptos de nación moderna. Derivados de la Revolución Francesa, en su amplia mayoría, esta constitución de una simbología común para la construcción de identidades también comunes, hizo partícipe a la estatuaria, de manera muy especial, en la erección de monumentos públicos. En sus inicios, monumentos de carácter efímeros -heredados de la tradición hispano barroca- donde los ideales clásicos regían el ámbito artístico y su expresión simbólica, especialmente difundidos en el proceso emancipatorio. Monumentos como el que mandó a construir la municipalidad de Santiago en 1818 en honor al General San Martín consistente en una columna de orden corintio, cuya cúspide "sostenía un mundo sobre 
el cual estaba la vocinglera i alada Fama anunciando con el clarín a los pueblos de América, las victorias del Libertador de Chile" y fuera localizado frente al Palacio del General2. Adornadas con balaustradas y sostenidas por columnas, figuras como el genio de la Victoria, la Fama y la Libertad se convirtieron en los principales motivos iconográficos de estos monumentos.

Pero será en la segunda mitad del siglo XIX donde se reafirmarán tanto el concepto republicano como la enseñanza de las artes, a través de un imaginario de carácter no sólo oficial, sino también alusivo a la construcción intelectual y visual de una identidad nacional a través de la apertura de la Academia de Bellas Artes en 1849. De esta manera, sus primeros directores, el pintor Alejandro Ciccarelli y el escultor Augusto François, entablaron la disciplina y los modelos basados en los ideales davinianos y el concepto de belleza clásica, que se ven reflejados en los planes de estudio que debieron cursar los jóvenes artistas nacionales. Las prácticas de representación basados en los cánones occidentales clásicos fueron base en la construcción simbólica en torno a las nociones de gobernabilidad, constituyéndose en referentes estilísticos donde predominó el principio historicista y el ideal ilustrado.

Tal vez el imaginario más difundido en la República fue el rescate de los héroes de los referentes bélicos, que buscaban reafirmar el concepto de nación como ente territorial y discurso simbólico; no sólo a través de escultura conmemorativa, sino también a través del culto a los muertos en batalla para la pervivencia de la moral tradicional criolla cuando ésta se encontraba en confrontación con nuevos grupos sociales. Tal es el caso del inusitado culto a los caídos en el combate Naval de lquique en 1879 y donde la tumba de su principal figura, el Capitán Arturo Prat, se convirtió en lugar de recurrente peregrinaje en la ciudad de lquique, hasta que sus restos fueron trasladados al monumento-mausoleo de Valparaíso en 1886. Veinte años antes, ocurría un fenómeno similar cuando Benjamín Vicuña Mackenna gestionaba el traslado de los restos de O'Higgins desde Lima a Santiago. En este sentido, el imaginario chileno encontró su referente en la imagen de los patriotas, modelos que buscaban edificar una memoria gloriosa y cuyo repertorio iconográfico fue ampliamente establecido por el pintor José Gil de Castro a inicios del siglo XIX y a través de la presencia de un importante grupo de pintores quiteños que habían trasladado sus talleres a ciudades como Santiago, Valparaíso y Concepción. Medio siglo después José Miguel Blanco, escultor chileno, contribuyó a la creación de una nueva galería de hombres ilustres a través de la representación de prominentes del Ejército y del mundo intelectual del pais, entre los que destacan las figuras de Miguel Luis Amunátegui, Domingo Faustino Sarmiento, Ignacio Domeyko y el General Marcos Maturana.

La consolidación económica del país y el progreso en materia artística, fue vista como un motor para el desarrollo "del culto a lo bello" y "al buen gusto", que se proyectó en una unidad discursiva de un grupo social del siglo XIX. De este modo, los bustos y retratos fueron del agrado de la sociedad chilena lo que permitió el incremento del mercado del arte $y$, junto a ello, la falsificación de obras por "improvisados escultores o artistas de mala lei"3. De este modo, es posible inferir la alta demanda que tuvieron estas obras por la burguesía adinerada, reuniendo tanto la visión social como artística de la clase conservadora y marcando la pauta sobre la cual la sociedad debía regir su "gusto" estético. El uso de esta fabricación de "identidad nacional" ocurría en torno a discusiones entre intelectuales y la oligarquía tradicional que escogió su propia visualidad a través de la selección de los medios que se ajustaban mejor a sus propios intereses. "¿Dónde la estatua poner/Que el pueblo no la haga trizas?", preguntaba el joven periodista Juan Rafael Allende en 1897 a raíz del proyecto de monumento a Manuel Montt y Antonio Varas, y que refleja estos enfrentamientos entre las clases dirigentes del país.

La realidad nacional en el ámbito de la constitución de clases sociales, presentaba fuertes diferencias que se mantenían desde el período anterior. El dominante recibía el nombre de aristocracia, sin embargo, no se trataba de una aristocracia en el sentido clásico del término, que tiene que ver con linajes y determinados modos de existencia social, sino simple y llanamente de la clase propietaria de la tierra y del poder político o lo que definiremos como élite. Esta élite, un círculo poco numeroso y de fortuna escasa, si se le compara con los verdaderamente acaudalados del resto de América, estaban poco o nada cultivados en el sentido del respeto y ejercicio de las bellas artes lo que les valió, en más de una oportunidad, fuertes criticas de parte de los artistas nacionales que cuestionaban el "negado gusto artístico de nuestros aristócratas millonarios" 
El marco general de costumbres, usos y recursos es igual para toda esta élite, pero su actitud frente a los movimientos culturales que se viven -por ejemplo, ante el Romanticismo- admite matices de importancia. Así, aquéllos definidos como moderados se mantenían apegados a una religiosidad "a la española", heredada de los tiempos coloniales y eran refractarios instintivos a las reformas y a los cambios bruscos, por lo que se presentaban menos receptivos a ideas libertarias y creativas (Sánchez, 1942). En términos políticos, sin embargo, este grupo se manejaba bajo los idearios republicano liberales, pero no deja de ser eminentemente una élite tradicional que se sustentaba en la economía agrícola y en el orden social señorial; más interesada en la pervivencia de éste, con la sumisión de las clases populares y la mantención del orden jerárquico que sostenía a la oligarquía.

A partir de 1827 y 1830, se comenzó a vivir un proceso de europeización cuyo modelo fue Francia, desde donde se difundieron las ideas ilustradas y positivistas de los pensadores europeos en establecimientos como el de Manuel Silvela y García de Aragón donde "acudieron a formar como una colonia estudiantil en el centro de la Europa, jóvenes peninsulares, chilenos, arjentinos, peruanos, colombianos" (Pérez Rosales, 1886, VIII). Y que a su regreso contribuyeron a cambiar las costumbres de la sociedad, aportando al imaginario local y al rechazo a la tradición en las páginas de pasquines criollos liderados por jóvenes literatos, junto a la aparición de talleres independientes de pintores y escultores. Pero este despertar tarda en afianzarse en Chile y sólo puede hacer su aparición cuando el país alcanza la estabilidad política y económica que hereda del ministerio de Diego Portales y tras el importante influjo de intelectuales argentinos, como Domingo Faustino Sarmiento, que huyen de la tiranía de Rosas y que traen consigo idearios liberales ${ }^{6}$.

En términos económicos, a partir del siglo XVIII y en los primeros decenios del siguiente, se genera en el país un importante auge derivado de la acción eficiente de las autoridades gubernamentales. Este desarrollo económico también debe considerarse una consecuencia de las reformas llevadas a cabo por los Borbones, especialmente las que dicen relación con el comercio y el incremento del contrabando en Chile. Tras el decaimiento económico producido por las guerras de Independencia y su posterior reorganización, surge un proceso de reestructuración económica fomentando el desarrollo de la capitalización básica: agricultura y minería.

El mercado agrícola comenzó a repuntar al finalizar la lucha contra el Virreinato del Perú, que en el período independentista había cortado la importación de productos chilenos. La producción del mineral de plata se vio reforzada tras el hallazgo del Mineral de Chañarcillo, ubicado al sur de Copiapó en 1832, que permitió el aumento considerable de la producción argentífera nacional. En Europa, la Revolución Industrial demandó una gran cantidad de cobre, y el buen precio alcanzado por este mineral estimuló su búsqueda y explotación en Chile a mediados del siglo XIX. Así, el auge de las exportaciones mineras y agrícolas permitió la acumulación de capital por parte del empresariado, que luego fue invertida en obras de variada indole. Estas inversiones, constituyeron una capitalización inicial asegurando la riqueza privada, que fue la base de un gran desarrollo económico.

De esta manera, las primeras décadas republicanas fueron favorecidas por el desenvolvimiento de la economía mundial que estimuló las exportaciones, generando inversiones en ferrocarriles, obras de regadío y otros adelantos. Junto con ello, se echan las bases para una renovación cultural, dando importancia a la educación pública y a la contratación de maestros extranjeros. La estabilidad política que se gesta entonces, aleja el recuerdo de la inestabilidad y los desórdenes anteriores a 1830.

Lo anterior, lleva a deducir que toda una generación de hombres, nacidos entre 1817 -período de la llamada Anarquía- hasta 1837 -muerte de Portales-, no habian sido testigos de los desórdenes políticos ni del autoritarismo portaliano, por lo que reciben con mayor fuerza otros idearios como el romanticismo europeo, el liberalismo parlamentario y el laicismo religioso (Bravo, 1992, 13). Lo que se estaba produciendo, entonces, era un desequilibrio de los sistemas ideológicos del siglo XIX. El núcleo social dominante permanecerá fundamentalmente idéntico en su composición desde la monarquía ilustrada hasta la república ilustrada, pero entre los jóvenes que se forman durante ese período se gestarán las tendencias liberales más doctrinarias esta vez, que no estarán conformes con el autoritarismo ni el dominio de la élite tradicional. Desde este punto de vista, los monumentos se transformaron en constructores de imaginarios colectivos que diseñaron, 
a su vez, una significación histórica sustentada en los discursos partidistas que manejaron ambos estamentos sociales.

"La Independencia -escribió el pintor uruguayo Juan Manuel Blanes-, los Carrera, O'Higgins, Chile, en suma, es una mina inagotable para los artistas que él forma y para el artista de la América española" (García Viera, 1998). ¿Pero son los héroes de la Independencia los únicos modelos que conviven en el mundo nacional? ¿Hacia dónde evoluciona el imaginario establecido por la República?

La pedagogía de la imagen actuó sobre dos líneas fundamentales, por una parte, en el espíritu de construcción identitaria para la formación cívica y por otra, en la educación del ciudadano en los preceptos de la moral burguesa.

La prolongación de la pintura de santos y el género del retrato, el fortalecimiento de la imagen mariana en la Virgen del Carmen y los imaginarios femeninos en cuanto madres y huachos en la constitución de alegorías del mestizaje chileno -tema que ha sido identificado por la antropóloga Sonia Montecino-, se constituyeron en algunas de las temáticas de identidad alternativas que se gestaron a lo largo del siglo XIX.

Un creciente interés democrático hacia las clases más desposeídas, permitió el surgimiento de diversas manifestaciones culturales que se aglomerarán en sociedades de tipo político y literarias que estimularán la conciencia nacional. El despertar intelectual que motiva el desarrollo económico y el espíritu conciliador del gobierno, sumado a la permanencia de intelectuales extranjeros sudamericanos, el interés científico y artístico de los europeos y la presencia de jóvenes chilenos interesados en renovar el espíritu artístico del país, permitieron un desarrollo cultural cuyas inquietudes se prolongarán hasta principios del siglo XX.

El recuerdo de la colonización española, pareció quedar relegada a una suerte de ficción historiográfica que prefirió plasmar el imaginario de la Independencia y no el pasado colonial. "Los hombres ilustrados de España $i$ de América fraternizaban en las nuevas ideas en que ambos continentes buscaban su rejeneracion" y cuyos alcances daba paso a una ideologización de un nuevo acercamiento con España y el reinicio del intercambio comercial (Pérez Rosales, 1886, VIII). El restablecimiento de las relaciones diplomáticas vigorizó la figura de Pedro de Valdivia que se materializó en diversos homenajes realizados por las autoridades, entre los que destaca el encargo al pintor español Eugenio Lucas sobre un retrato del Fundador de Santiago. El auge de la pintura de historia a fines del siglo permitió, también, nuevas imágenes en torno al Gobernador y Capitán General del Reyno de Chile, en las que sobresalieron "La muerte de Pedro de Valdivia" de Nicolás Guzmán (1875) y la "Fundación de Santiago" de Pedro Lira (1898). También en 1875 se instaló en la Quinta Normal de Agricultura una escultura de 3,00 mts. de alto del Capitán, obra del italiano Costoli (Fig. 1). Si bien la escultura fue muy bien recibida por la crítica, su emplazamiento en las puertas de la Exposición Internacional -hito de la difusión de la modernidad en la nación chilena- no lo fue tanto, ya que se consideró que "no ha sido ménos oportuno ni feliz el

1. Aristodemo Costoli (1803-1871), Monumento a Pedro de Valdivia. Publicada en "La Ilustración española y americana" (1892).

Fuente: todocoleccion.net.

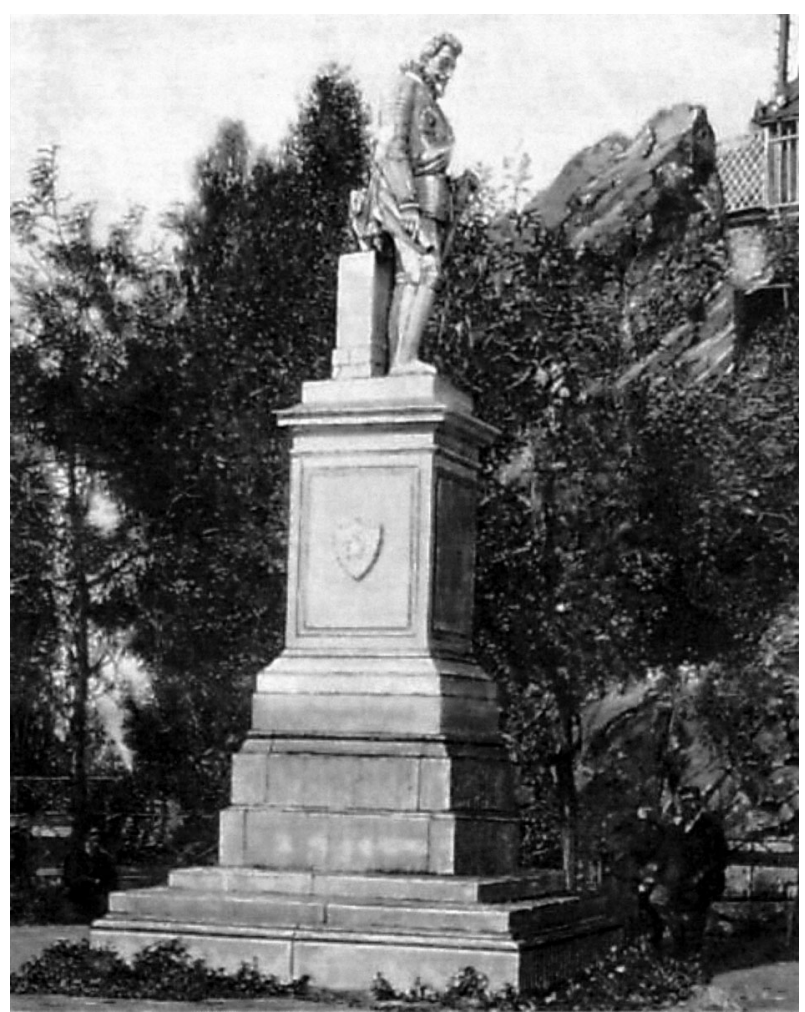


pensamiento que halló tan favorable acojida en el Directorio de la Esposicion, para colocar al primer representante de la conquista en la entrada de nuestra gloria del porvenir"

Treinta y cinco años después, en la Celebración del Centenario, se publicaron tres caricaturas del dibujante Moustache en la "Revista Zig-Zag", en torno a lo que se consideraron "monumentos ofensivos" a la imagen de España donde sobresale, precisamente, el de Pedro de Valdivia de Costoli sobre el cual el dibujante señala que "hemos mandado a la punta del cerro. Eso si que es ofensivo"8.

Otro monumento que fue trasladado al Cerro Santa Lucía en 1900 fue el "Caupolicán" de Nicanor Plaza. Admitido en 1868 en el Salón de París, la obra -una alegoría a los indígenas americanos y no un retrato del caudillo araucano- fue trasladada a Chile con el nombre de Caupolicán, bajo el cual fue incorporada a la memoria nacional (Fig. 2). El palimpsesto bélico de la conquista $y$, por ende, el sometimiento indigena fue apropiado en un nuevo discurso que enfrentaba visiones divergentes sobre la historización de la nación. Así, por una parte la imagen del araucano surgió como un ideario de la lucha anticolonial y sobre el cual los emancipadores encontraron la mejor forma de ilustrar el ideal de la libertad. Un claro ejemplo es la logia masona "Lautaro", formada por Francisco de Miranda y en la que participaron tanto Bolívar, O'Higgins como San Martín; la imagen del araucano fue difundida en la emblemática independentista hasta 1834 y promocionada en periódicos como "El monitor Araucano". Pero a poco andar, el territorio de Arauco se transformó en un problema político-económico de la República y que llevó, también, a la transformación de la imagen del indígena.

El reconocimiento de la propia territorialidad chilena promovió una narrativa del paisaje y que fuera promovida, también, por los intelectuales liberales invitando a la incorporación de este género de la pintura como asunto de los artistas y potenciando teorías geopolíticas como la del "Chile fantástico" apoyada en los argumentos de Amunátegui y Morla Vicuña respecto a los límites geográficos. El espacio de frontera se convirtió en un tema político no sólo en relación a las cuestiones limítrofes con los paises vecinos, sino también por cuanto era necesario asegurar la estabilidad, tanto en relación con los indígenas como con los hacendados y el poder comercial que representaban. Por otro lado, la ingobernabilidad de este territorio no
2. Nicanor Plaza (1844-1918), Caupolicán. Fotografía publicada en la Revista Selecta, Santiago de Chile, año II, n. ${ }^{\circ} 1$, abril de 1910.

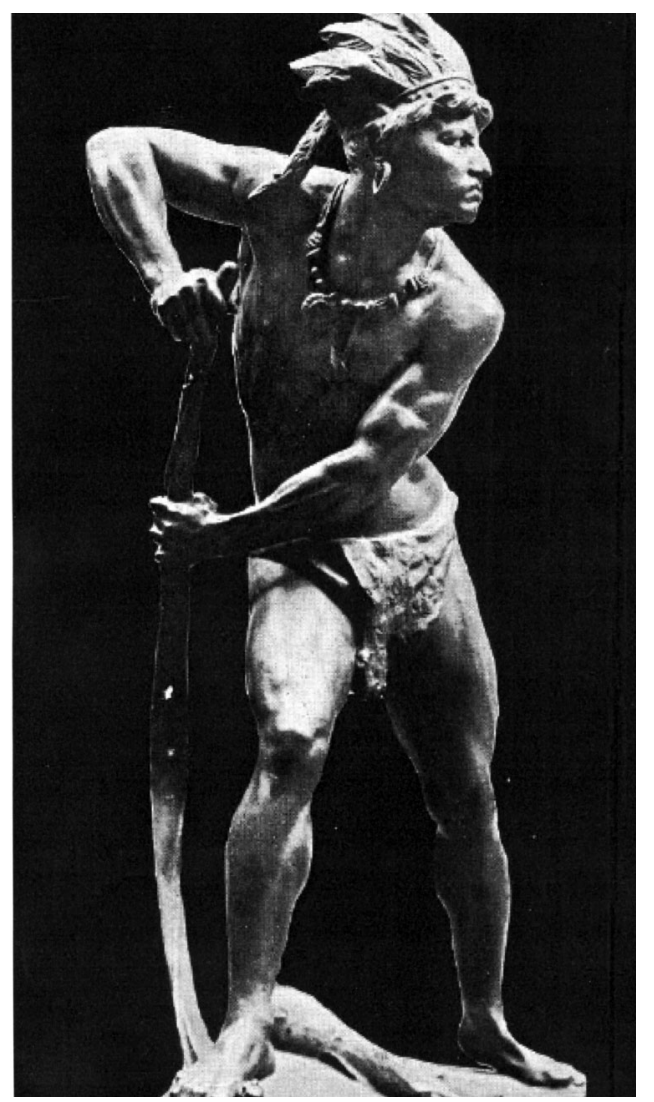

condecía con la estabilidad soberana que significada un Estado moderno como el chileno, desde el cual se configuraron imágenes sobre el indígena como signo de salvajismo y ferocidad reafirmadas por los saqueos, malones y raptos acaecidos desde el siglo anterior en las zonas fronterizas. "Tales son los semi-dioses de Ercilla!" (Vicuña Mackenna, 1868 , 4), señalaba Vicuña Mackenna, afianzando la visión del indígena incapaz de autogobernarse y asociándolo a la mentira, la barbarie, lo corrupto y que fuera ampliamente difundido por la literatura y las imágenes sobre las llamadas "cautivas blancas" -tema que ha destacado la historiadora del arte Laura Malosetti- que se repiten en los casos chilenos y argentinos.

"Es cierto que el bárbaro es valiente; pero ¿qué salvaje no lo es? Es cierto que el indio defiende su suelo; pero lo defiende porque ódia la civilización, ódia la lei, el sacerdocio, la 
enseñanza" (lbid, 4). Aduce el mismo Vicuña Mackenna en 1868 como diputado de Valdivia, alentando la ocupación del territorio ya que "la conquista de los pueblos bárbaros, ociosos i vagabundos, es perfectamente lejítima" (Ibid, 16); ocupación que no sólo unificó al pais sino también potenció y favoreció el fortalecimiento comercial de los hacendados de la zona sur en un discurso elaborado por la misma élite criolla que, hasta ese momento, no había incorporado al indio en sus prácticas ideológicas. Esta visión genera enfrentamientos entre intelectuales como José Victorino Lastarria, que apoyaba la resistencia araucana, y aquéllos que no sólo la criticaban, como el caso de Vicuña Mackenna, sino también la extendían hacia la actitud indigenista que habian adquirido algunos representantes de la clase intelectual y política de Chile. Críticos de estos últimos serán el argentino Domingo Faustino Sarmiento y el venezolano Andrés Bello, quienes abogaban por borrar el pasado colonial y su visión fatalista (Navarro, 2005). Una imagen que contrastaba con el indígena aliado que había encontrado al criollo blanco en contra de la colonización a principios del siglo, apoyada en la poética construida por Alonso de Ercilla en su "La Araucana" tres siglos antes y que fuera, también, materializada en el Himno Patrio en 1847.

Pero a fines de siglo XIX, nuevamente la imagen del indígena comienza a ser rescatada por esta nueva oleada de jóvenes intelectuales que ven en la figura de los "marginados" del aparato estatal, una nueva forma de preservar la identidad nacional y sus sujetos presentes por cuanto se consolidaba el concepto de ciudadanía popular. Es así como aparece "Caupolicán" y otras esculturas de Plaza como "El Toqui" y "El jugador de chueca", que junto con la "Araucana" de Virginio Arias, se incorporan en la visualidad chilena. Esta imagen del "buen salvaje" y la alteridad difundidos ya en el siglo XVI, fue reforzada por la presencia objetiva de la fotografía que realizaran viajeros como Paul Treutler, Rafael Castro y Ordóñez en comisiones científicas, y las de Odber Heffer y Gustavo Milet cuyas imágenes fueron de amplia circulación en Chile y el extranjero, además de las fotografias de las misiones capuchinas a partir de 1896 y su visión pedagógica sobre los pueblos "pacificados".

Si bien para 1842 se venían consolidando ideas fundamentales sobre la transformación del hombre americano "en tanto hombre y ciudadano de Repúblicas" difundida por Andrés Bello (Rubilar, 2004, 554), otras manifestaciones plasmadas en "La Sociedad de la Igualdad" de Santiago Arcos y Francisco Bilbao, y la consolidación de una nueva élite intelectual, buscaban en el liberalismo popular la necesidad de reivindicación del pueblo a través del aumento de los niveles de instrucción, mejoras salariales, moralización de los sectores populares; acciones que se percibian como una condición de la modernización y se relacionaban directamente con la tarea de construir nación, promoviendo la formación de ciudadanos. Este liberalismo popular tuvo su mayor expresión en la creación del Partido Democrático a fines de 1880, que rompe con el liberalismo de las elites, aun cuando se basa en los mismos ideales ilustrados y la confianza en las instituciones representativas del Estado (Grez, 2005, 110).

Pero cuando los conflictos bélicos en relación a los límites territoriales se hicieron presentes en 1836 con la Guerra de la Confederación Peruano-Boliviana y, luego, en 1879 con la Guerra del Pacífico, nacieron nuevos héroes nacionales que se concibieron como la encarnación de la raza chilena, a partir de miradas positivistas sobre la identidad nacional y que enfrentaron a los liberales en torno a la imagen popular y sus fines didácticos. Figuras disímiles como el "militar" y el "Roto", compartieron escena en la edificación de una visualidad identitaria en las manos de los artistas nacionales. Estos modelos de representación fueron los temas que movilizaron más recursos y gestiones para la construcción de una memoria histórica.

\section{"I ¿QUUIÉN ES MOYA?": OLIGARCAS Y LIBERALES EN LA INSTRUMENTALIZACIÓN DEL ROTO}

"¿Quién paga?... Paga Moya", sentenciaba Juan Rafael Allende ante las denuncias de desfalcos públicos, los derroches del fisco y el nepotismo del gobierno generado tras la guerra civil de 1891. "I ¿quién es Moya? Moya es el pueblo productor, el pueblo contribuyente, el pueblo obrero, el pueblo soldado, el pueblo marinero, el pueblo trabajador" (Allende, 1904, 54) ${ }^{9}$. El advenimiento del Parlamentarismo en Chile (1891-1925) consolidó el poder de la clase adinerada del país que se venía gestando desde 1870 mediante las reformas que fueron fortaleciendo el rol del Congreso Nacional. Junto a ello, surge una importante inestabilidad en torno a los límites de la ciudad y los suburbios en el proceso de crecimiento urbano de Santiago, la migración 
campo-ciudad y la crisis del campesinado (Fig. 3). En este proceso de migración surge el gañán o Roto, figura identificada por primera vez entre las décadas de 1830 y 1840 tras la guerra de la confederación peruano-boliviana, y que al poco andar se transformó en el apelativo que identificó a la raza chilena, al mestizo hijo del bastardaje, el "huacho" identificado por Montecino.

"Nuestro roto no puede quejarse de que para él seis dias de la semana sean de dolores, ni mucho menos que el séptimo sea de aburrimiento", declaraba la Revista "Instantáneas de Luz i Sombra" en $1901^{10}$ reforzando la visión del obrero ocioso, dado al alcohol y mujeriego que fuera ampliamente difundido en el siglo XIX y sobre el cual el Estado debía operar en su labor de ilustrarlo y asegurar sus libertades y derechos civiles y políticos, según consta en el discurso

3. Un roto, siglo $X I X$. En Chile ilustrado: guía descriptiva del territorio de Chile, de las capitales de Provincia, de los puertos principales (1872). Colección Biblioteca Nacional.

Fuente: Memoria Chilena.

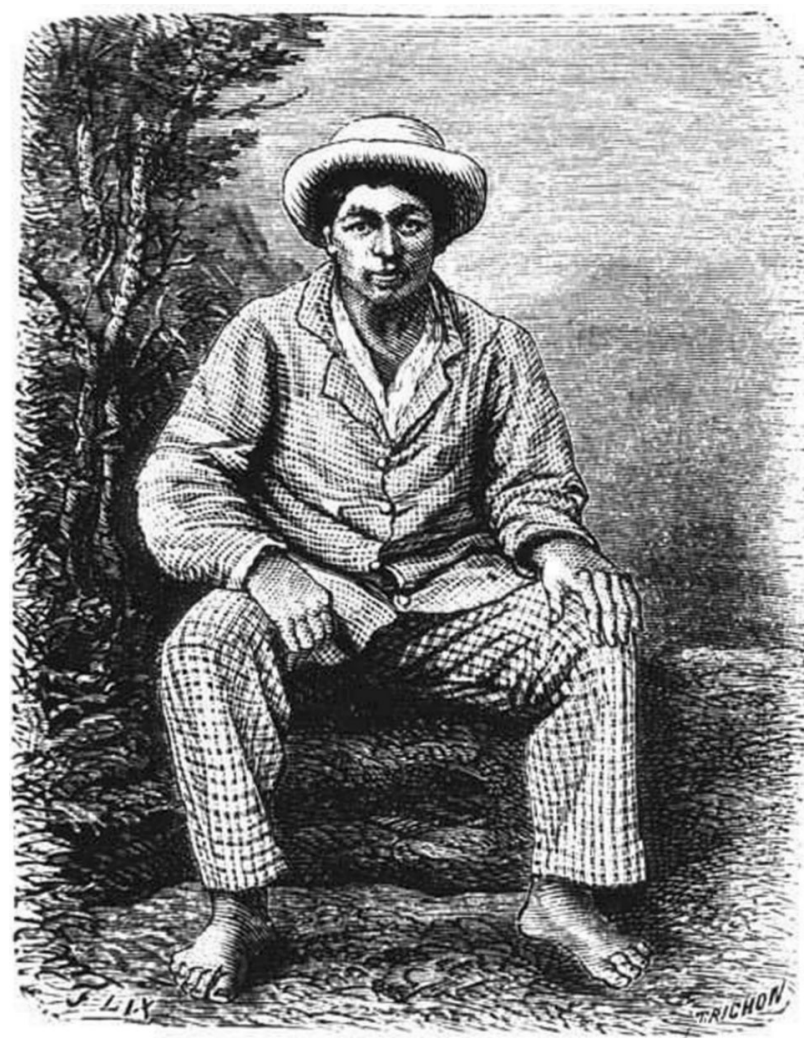

del Presidente Balmaceda en 1889 (Balmaceda, 1889). Pero también se le asignó un rol protagónico en los conflictos bélicos, resaltando su valentía y arrojo, una imagen de identidad nacional del hombre que "en la guerra es un león, junto á la mujer amada un cordero"11. Dos caras frente a un mismo tipo social, que perpetúan la imagen del "roto" hasta las primeras décadas del siglo XX e inmortalizado por Joaquín Edwards Bello en la novela homónima de 1920.

El gran momento del "Roto" vino con la Guerra del Pacífico (1879-1884):

"Nunca con más razón que en este instante podríamos afirmar que Chile es un pueblo de ciudadanos. Los obreros que en 1879 invadian los talleres, las fábricas o las construcciones de esta opulenta metrópoli comercial, empuñaron resueltamente la espada o el fusil, cruzaron el Pacifico, y vencieron y aniquilaron al enemigo en jornadas cuya fama ha recorrido el universo entero"m2.

El labriego transformado en obrero y el obrero en héroe, en una conceptualización forzada respecto al rol del gañán, que enfrenta a la élite en un esfuerzo por conservar sus valores tradicionales frente a una nueva burguesía adinerada. De esta manera, reconoció la condición pobre, miserable y débil del pueblo y prestó, entonces, más atención a los "Rotos" de la ciudad para constituirlos en instrumento de su propia "moralidad". Es así que el antiguo proyecto de arco de triunfo para la Batalla de Yungai de 1839 se transformó en el monumento al "Roto Chileno" erigido en 1888, realizado por Virginio Arias y que fuera presentado al Salón de París seis años antes. El monumento fue emplazado sobre una gruta de piedras en el cual figura el modelo francés del Defensor de la Patria, ajeno al imaginario del verdadero Roto que viste "sombrero de anchas alas, generalmente de paja y poncho", según lo describe Juan Serrado en su "Visita a Chile en 1895" (Serrado, 1898, 42). El personaje de Arias aparece vestido de labriego con la camisa y el pantalón arremangados, sosteniendo un fusil en la mano derecha, localizando tras él una gavilla de trigo y una pequeña hoz. Virgino Arias, nuevamente, ocupa la simbología del poder operante en Chile buscando la unión de la trilogía clásica por excelencia: verdad, vida y belleza.

Así, la figura del "Roto" se configura como la del "David" de Miguel Ángel, presentando una figura en tensión, la pierna derecha adelanta a la izquierda y el brazo izquierdo 
descansa sobre la figura del soldado, mientras que la derecha se eleva sosteniendo el fusil. La cabeza mira hacia la izquierda, el ceño fruncido, manteniendo los ojos fijos en su objetivo: el campo de batalla (Fig. 4). Pero más allá de su iconografía, el monumento representó simbólica y conceptualmente la inquietud de resaltar los valores patrios y de atraer como aliado al pueblo a favor de los intereses de la élite.

"El influjo de estos ideales así corporizados, levanta el alma de las muchedumbres, la arranca de brutales pasiones, la defiende de groseros apetitos, la hace volar, encendida por ardiente deseo, hácia la realización de esos tipos sublimes" (Zambrana, 1875, 34) ${ }^{13}$.

Señalaba Antonio Zambrana en 1875 en "El Correo de la Exposición" respecto al rol de la estatuaria. Sin embargo, el

\footnotetext{
4. Virginio Arias (1855-1941), Monumento al Roto Chileno. Fuente: Escultura Pública. Del Monumento Conmemorativo a la Escultura Urbana (2004).
}

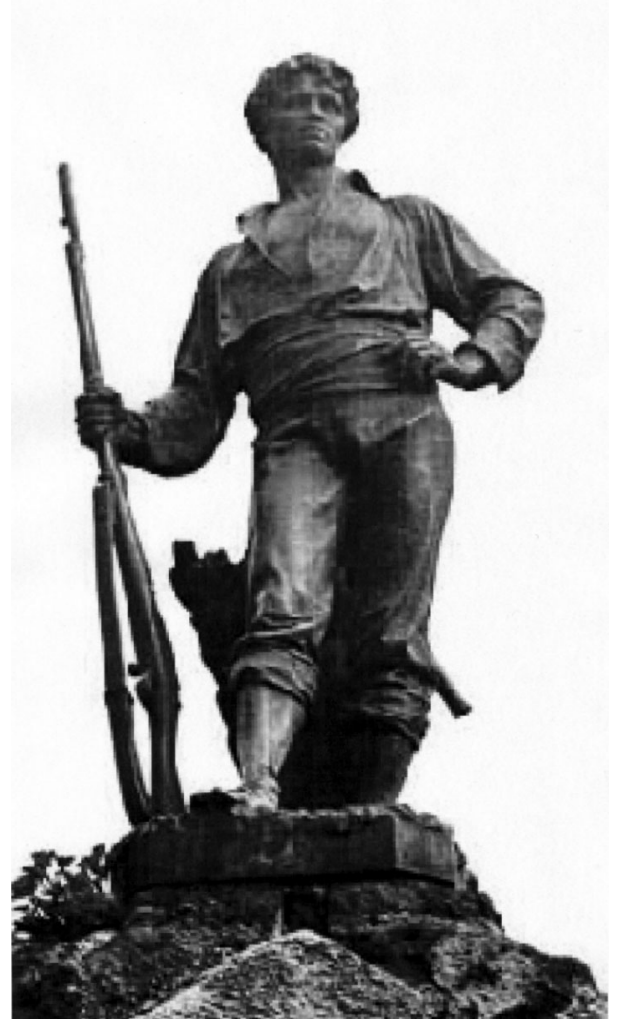

monumento resaltó las diferencias entre la oligarquía tradicional y la intelectualidad liberal, liderada por personajes como Juan Rafael Allende, periodista, dramaturgo y poeta, redactor de periódicos satíricos que hacían escarnio de la clase política, antioligárquico, anticlerical y liberal popular.

"Viendo los capitalistas que un Gobierno (el de don José Manuel Balmaceda) tenía la idea de hacer un ferrocarril que uniera a Valparaíso con Iquique (la ruina de los capitalistas salitreros); la de crear un Banco del Estado (la ruina de muchos banqueros); la de fomentar la instrucción pública en todo pais (la ruina del clero, explotador de la ignorancia de las masas populares), los aristócratas i millonarios de este país, en secreto cónclave, acordaron hacerle una revolución a ese Presidente con tendencias democráticas" (Allende, 1904, 51).

Enjuicia el periodista en el folletín "Obreros i Patrones" sobre la posición de la oligarquía y los grupos conservadores representados por el nuevo Presidente de la República, Jorge Montt tras la guerra civil que terminó con el suicidio de José Manuel Balmaceda. Guerra que llevó a nuevos "torrentes de sangre de Rotos", con 10.000 muertos en los campos de Concón y Placilla. Su posición anticlerical, las denuncias de desfalcos públicos, entre otras polémicas, caracterizaron su discurso que lo llevó a ser enjuiciado con la pena de muerte, que luego fue revocada.

En 1888, Allende publica en el pasquín "El Padre Padilla" una caricatura del monumento de Arias, al que denomina "Monumento al Roto... piojento" y en la cual aparece el joven soldado arrodillado con la mano en el pecho y acompañado de dos lechuzas montadas sobre una gruta de Nuestra Señora de Lourdes, localizando a su alrededor a los verdaderos Rotos y al clero, haciendo referencia a sus discrepancias políticas con este último sector (Fig. 5). "Como es cursi el llamado monumento, cursi, grosero e infame fue el discurso del Intendente Lazcano", quien resalta precisamente los intereses de la élite criolla sobre la clase trabajadora del país y que utiliza al Roto chileno según las necesidades coyunturales que le benefician (Allende, 1888) ${ }^{14}$. Por lo mismo, el monumento no fue bien recibido por la comunidad dado su evidente sentido oligárquico que fuera notado por el mismo Presidente Balmaceda y que llevó a una manifestación pública respecto a la destrucción de la obra de Arias. En "El Taller Ilustrado", fundado por el escultor José Miguel Blanco, se publica el 12 de noviembre 
de 1888 el artículo "El monumento de la Plaza de Yungai", donde se solicita la demolición de "tan ridícula obra, o por lo ménos disponga una modificación radical que la quite, en cuanto sea posible" (Blanco, 1888), pero la petición no prosperó y aún hoy podemos encontrar el monumento en la Plaza Yungai (Cortés, 2008).

Desde este punto de vista, los monumentos se transforman en constructores de imaginarios colectivos que contienen el sentido simbólico del Estado. La contundencia del mensaje se apoya o vincula, intransferiblemente, al espacio que lo circunda, a los hechos que rememoran y a

5. Juan Rafael Allende (1848-1909), Monumento al roto... piojento. Caricatura publicada en El Padre Padilla, Santiago de Chile, año V, $n^{\circ} 606,11$ de octubre de 1888.

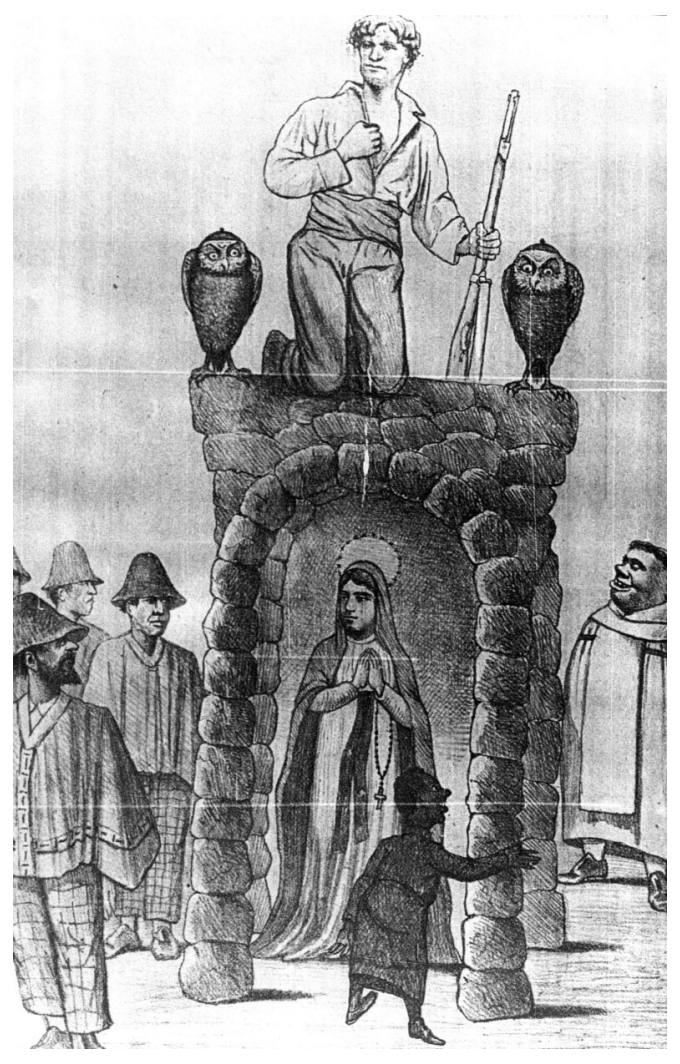

la estética de la representación donde la práctica artística y la práctica política como discurso, se presentan ligados el uno del otro.

"Pueblo laborioso, iadelante! Criad hábitos de economía $i$ sobriedad, i ese será el único camino por el cual podreis llegar a todas partes, en este país de igualdad i libertad.

Desechad las falsas teorías. En Chile el aire puro sobra i el más allá no tiene barreras" (Allende, 1888).

Alentaba Lazcano en su discurso de inauguración y ante el cual Allende responde,

\section{¿Qué el más allá no tiene barreras?}

Ese es un hecho, un exioma para los astrónomos, aunque nó para los teólogos.

I, si a este mundo volvieran, don Lazcano, los pobres rotos que usted há tiempo despachó a balazos para el otro, porque a medio dia entraron a robarle uvas a una de las viñas de usted, podrian asegurarle que el más allá de la tumba, único que conoce en Chile el hijo del pueblo, no tiene barreras como tampoco tiene barreras la estupidez de su señoria" (Ibid).

La visión paternalista de la élite que tanto critica Allende y los liberales populares, es la misma que asumen los intelectuales cuando se insta a la instrucción del pueblo, "proporcionándoles escuelas, ocios honestos i buenos ejemplos" para de ese modo saldar "Ias deudas que tenemos con los desheredados de este noble pueblo", según Nercasseau (lbid). Constituyendo a "oligarcas" y "pueblo" en culturas antagónicas y donde este último es visto como una masa ignorante y virtuosa a la vez. Dicotomías que se refieren a las diferentes miradas desde las cuales se percibe la imagen del "Roto": desde el paternalismo a la hostilidad y viceversa.

¿A quién creerle?/¿Al jóven ilustrado o al labriego de San Javier de Longomilla?" culmina Allende (lbid), resumiendo el enfrentamiento de los discursos de Lazcano, como representante de la élite, y Nercasseau, de los intelectuales, en un intento por establecer responsabilidades asumidas, finalmente, por "Moya". 
1 Publicado en el artículo de Juan Rafael Allende, "Monumento al Roto Chileno", El Padre Padilla, 9 de octubre de 1888, año $V$, n. ${ }^{0} 605$. Discurso de Enrique Nercasseau Moran en la inauguración del monumento en la Plaza Yungai.

2 El Sol de Chile, número 18, Santiago 6 de noviembre de 1818, p. 7

3 El Taller llustrado, 8 de abril de 1889.

4 El Jeneral Pililo, 11 de noviembre de 1897.

5 "El arte a cuartillo el atado", Poncio Pilatos, año III, n. ${ }^{\circ} 348,17$ de diciembre de 1898.

6 Diego Portales Palazuelos (17931837), ministro del Presidente de la República don José Joaquín Prieto (1831-1841). Durante su segundo ministerio, Portales habria permitido que la sociedad republicana se mantuviera bajo la égida tradicional de la Iglesia y se habría preocupado de la reorganización de esta última, además de levantar paulatinamente las clases más bajas de la sociedad nacional. Sin embargo, los nuevos postulados de la historia de Chile apuntan a un ministro Portales de corte republicano liberal, que se manifestaba a favor de un autoritarismo social. En este sentido, para Jocelyn-Holt el ministro Portales habría sido un dictador, sin que esto significase que ideológicamente se encontrara en contra del ideario republicano liberal, sino que impulsaba objetivos de gobierno absolutamente autoritarios.

7 "La Estatua de Pedro Valdivia", El Correo de la Exposición, 16 de septiembre de 1875, año I, n. ${ }^{\circ}$ I, p. 7.

Recibido: 7 de marzo de 2008

8 "Monumentos ofensivos", Revista Zig-Zag, 25 de junio de 1910. El auAceptado: 17 de mayo de 2008

miento del monumento que se realiza en 1877 en el Cerro Santa Lucía. La frase "mandar a la punta del cerro" es un chilenismo que dice relación con echar a alguien no deseado.

9 La frase "Paga Moya" es un chilenismo que se utiliza cuando nadie se hace responsable por una deuda.

10 Instantáneas de Luz i Sombra, 22 de diciembre 1901, año II, n. 92.

11 Instantáneas de Luz i Sombra, 22 de diciembre 1901, año II, n. ${ }^{\circ} 92$.

12 Discurso del Ministro del Interior en la Ceremonia de distribución de medallas a los cuerpos de Valparaíso, 21 de enero de 1883. El Ferrocarril 23 de enero de 1883.

13 "A propósito de escultura", El Correo de la Exposición, 16 de octubre de 1875, año I, n. ${ }^{\circ} 3$, p. 34.

14 Publicado en El Padre Padilla, año V, n. ${ }^{\circ}$ 605, 9 de octubre de 1888.

\section{BIBLIOGRAFÍA}

Allende, Juan Rafael (1904): Obreros i patrones: conflicto entre el capital $i$ el trabajo en Chile, su única solución, Imprenta Enc. León Víctor Caldera, Santiago.

Bravo, Bernardino (1992): "Una nueva forma de sociabilidad en Chile a mediados del siglo XIX: los primeros partidos políticos", en W. AA., Formas de sociabilidad en Chile. 1840-1940, Fundación Mario Góngora, Editorial Vivaria, Santiago.

Cortés, Gloria (2008): "De plumas y pinceles: texto y visualidad en la crítica de arte en Chile, en la segunda mitad del siglo XIX", Revista Intus Legere, Universidad Adolfo Ibáñez, Santiago.

Grez Toso, Sergio (2005): "El Proyecto Popular en el siglo XIX", en Manuel Loyola y Sergio Grez, Los proyectos nacionales en el pensamiento político 
y social chileno del siglo XIX, Ediciones Universidad Católica Silva Henríquez, Santiago, pp. 107-112.

Ministerio de Educación Ministerial y Archivo General de la Nación (1998): Testamento de José Miguel Carrera, Advertencia de Abelardo Manuel García Viera, Edición en homenaje al Presidente de Chile Eduardo Frei, Montevideo, Colección de Documentos, Imprimes S.A.

Navarro Floria, Pedro (2005): "La conquista de la memoria: La historiografía sobre la frontera sur Argentina durante el siglo XIX", Revista Universum. [online], vol. 20, n. 1 [citado 05 noviembre 2007], pp. 88-111. Disponible en la World Wide Web:

http://www.scielo.cl/scielo.php?script=sci_ arttextctpid=S0718-2376200500010 0007\&lng=es\&nrm=iso >. ISSN 07182376.

Pérez Rosales, Vicente (1886): Recuerdos del pasado: 1814-1860, Impr. Gutenberg, Santiago.

Rubilar, Luis (2004): "Bello-Educador: Identidad De Rol Fundamental", Educere La Revista Venezolana de Educación, año 8, n. $^{\circ} 27$.
Salinas, M. (2004): "Juan Rafael Allende, 'El Pequén', y los rasgos carnavalescos de la Literatura Popular Chilena del Siglo XIX", Revista Historia, Santiago, junio, vol. 37.

Sánchez, Luis Alberto (1942): Historia General de América, Ed. Ercilla, Santiago.

Serrado, Juan (1898): Visita a Chile en 1895, Buenos Aires, s/e.

Vicuña Mackenna, Benjamin (1868): La Conquista de Arauco, Discurso pronunciado en la Cámara de Diputados en su sesión de 10 de agosto, Impr. del Ferrocarril, Santiago.

Voionmaa, Flu (2004): La Escultura Pública. Santiago 1792-2004, Ocho Libros Editores, Santiago.

\section{Archivos y Publicaciones Periódicas}

El Coquimbo (1889): "Discurso del Presidente Balmaceda en El banquete que la ciudad de La Serena celebró en su honor el 22 de marzo de 1889", El Coquimbo, 23 de marzo.

El Correo de la Exposición (1875): "La Estatua de Pedro Valdivia", El Correo de la Exposición, año I, n. 1, 16 de septiembre.

El Correo de la Exposición (1875): "A propósito de escultura", El Correo de la Exposición, año I, n. ${ }^{\circ}$ 3, 16 de octubre.

El Ferrocarril (1883): "Discurso del Ministro del Interior en la Ceremonia de distribución de medallas a los cuerpos de Valparaíso, 21 de enero de 1883", El Ferrocarril, 23 de enero.

El Jeneral Pililo (1897): "Ilustración Monumento Montt-Varas", El Jeneral Pililo, n. ${ }^{\circ} 203,11$ de noviembre.

El Padre Padilla (1888): "Monumento al Roto Chileno", El Padre Padilla, año V, n. ${ }^{\circ} 605,9$ de octubre.

El Padre Padilla (1888): "Monumento al roto... piojento", El Padre Padilla, año V, n. ${ }^{\circ} 606,11$ de octubre.

El Sol de Chile (1818): N. ${ }^{18}, 6$ de noviembre.

El Taller llustrado (1888): "Monumento de la Plaza Yungai", El Taller Ilustrado, año IV, n. ${ }^{\circ} 155,12$ de noviembre.

Poncio Pilatos (1898): "El arte a cuartillo el atado", Poncio Pilatos, año III, n. ${ }^{\circ} 348$, 17 de diciembre.

Revista Zigzag (1910): "Monumentos ofensivos". Revista Zig-Zag, 25 de junio. 